\title{
A methodological approach to implement on-site construction robotics and automation: a case of Hong Kong
}

\author{
Wen Pan ${ }^{a}$, Rongbo Hu ${ }^{\text {a }}$, Thomas Linner ${ }^{a}$ and Thomas Bock ${ }^{\mathrm{a}}$ \\ ${ }^{a}$ Chair of Building Realisation and Robotics, Technical University of Munich, Germany \\ E-mail:wen.pan@br2.ar.tum.de,rongbo.hu@br2.ar.tum.de,thomas.linner@br2.ar.tum.de, thomas.bock@ \\ br2.ar.tum.de
}

\begin{abstract}
The public housing construction industry in Hong Kong faces conspicuous challenges of high demands, safety, an ageing workforce, inconsistent quality and stagnant productivity. Compared to the manufacturing industry, the degree of automation in the construction sector lags behind. Based on the ongoing consultancy project commissioned by the Construction Industry Council (CIC) in Hong Kong, the aim of this paper is to evaluate the current on-site construction operation and to identify the existing bottlenecks that can be enhanced by implementing robotics and automation. In the current housing construction field, the systematic and scientific method to approach this type of undertaking, especially when closely associated with the industry and authorities, has not been comprehensively discussed. Therefore, this paper highlights the activities that signify these objectives, which include five key activities: literature review, industry survey, on-site case study, co-creation workshops and potential pilot project. The key activities forming the backbone of the project and the outcomes will be illustrated. As a result, a range of proposed robotic applications that are tailor-made for Hong Kong public housing industry are recommended and hierarchically categorised. The results will epitomise the applicable methods that are required when executing the similar type of consultation project. In addition, the findings will inspire the construction industry to initiate and explore innovative, compatible as well as feasible solutions to the implementation of the robotic application in the future.
\end{abstract}

Keywords -

Construction robotics and automation; Methodology; Public housing construction; Hong Kong

\section{Introduction}

The Hong Kong Public Housing Construction (PHC) sector experiences three major challenges: first, to satisfy the increasing demand; second, to achieve affordable price, and third, to address demographic changes. In recent years, the manufacturing sector has adopted robotic and automation technology. This paradigm has achieved obvious implications in regard to increased productivity, affordability, constant quality, and improved safety.

In general, compared to the manufacturing industry, the degree of automation lags behind in the construction industry, and the implementation of construction robotics and automation may hold the key to solve the aforementioned challenges [1]. Therefore, the Construction Industry Council Hong Kong (CIC) commissioned the Chair of Building Realization and Robotics $\left(b^{2}\right)$ at Technical University of Munich (TUM) to research and develop construction robots and automation strategies that are tailor-made for the PHC in Hong Kong. This paper documents the on-going project that demonstrates the research objectives, methods and evaluates the outcomes of the current project phase, as well as defines the remaining tasks.

\section{Public housing construction (PHC) in Hong Kong}

To gain a basic understanding of the Hong Kong PHC sector is decisively important when proposing tailormade methods in developing construction robots and automation strategy for Hong Kong. Hong Kong is situated at the southern tip of the mainland China, which consists of three main islands, Kowloon, Hong Kong, and New Territories. The development of construction is always challenged by the hilly terrain and high population density [2].

Public housing in Hong Kong, which can date back 50 years ago, has a long history of overcrowding and 
growing demand. Over 48.8 percent of the population in Hong Kong live in public housing estates today [3]. According to the government census, the average living space per person is $13.2 \mathrm{~m}^{2}$. Demographically, increasing numbers of retirees will impose more pressure on public housing demand. The government estimates that the housing supply target for the year 2017-2018 is 460,000 units. To make things worse, the housing prices have skyrocketed in recent years, and young people find it extremely difficult to climb up the property ladder. Therefore, the government needs to progressively response by closely working with the PHC sector to solve the aforementioned issues [4].

\subsection{Challenges and hypothesis}

To be able to catch up with the increasing housing demand, the PHC sector must improve its productivity and speed up the construction lead-time. As a result of the high housing price and construction cost, the quality and standard of the final finishing has to be high to avoid any criticism or even rejection from the Housing Department (HD) or the tenants. As a result of population ageing, skilled workers are scarce in the construction market. The construction industry has to transform its traditional public image from a dirty, dangerous and demeaning industry to a safe, attractive and prosperous one. Subsequently, implementing construction robotics and automation technology will potentially increase productivity, enhance construction quality, and improve on-site operational safety. In addition, it has the potential to transform the status of blue-collar construction workforce to the technology-focused and highly skilled workforce. With this paradigm shift the construction industry might has the potential to attract younger workers to engage in the construction trade [5].

\subsection{Research objective and gaps}

In general, construction processes are complicated, including many parallels, and sequential tasks are carried out seamlessly. Many stakeholders are involved in each critical phase to ensure that the project is on time and on a budget as well as satisfies key stakeholders' requirements. Despite what have been mentioned, many other factors could also influence the construction process, such as the technological, social, economic factors, and political measures. The main objectives of this project are: first to evaluate current status of the PHC sector by investigate existing construction operation, labour market, regulations and government legislation, then to identify the challenges, key stakeholder's requirements, and to validate key construction processes that can be improved by implementing on-site construction robotics and automation. Finally, a range of robotic applications will be tailor-made and proposed for the PHC sector, bearing wider audiences once the industry sector is reformed. For example, the future construction sector will expose a cross-disciplinary characteristic where many industries coexist and collaborate. In this sense, upgrading the performance of the construction industry not only has positive impact on one industry but also will grant much greater contribution to the prosperity of Hong Kong.

Research has been done on the development of construction robots. However, it has not been studied sufficiently in-depth, and often times only the design concept, hardware and software applications are demonstrated. Thus, limited research topics were particularly conducted related to the PHC in Hong Kong. Existing research does not emphasise issues related to the early stage of the construction robotics development. Therefore, the consultancy project fills the void and demonstrates a comprehensive method that emphasises research methodology in regards to the early stage of the construction robotics development. For example, how to structure an applicable approach that encourages the collaboration between the key stakeholders. It also explores how to interpret the accumulated data into universal requirements that can be further implemented as practical designs. Furthermore, the project explores to develop a practical design concept that reflects the research objectives and suits the practical market demands.

\section{Methods}

In order to systematically execute the consultancy project, the project has been divided into five phases (Figure 1).

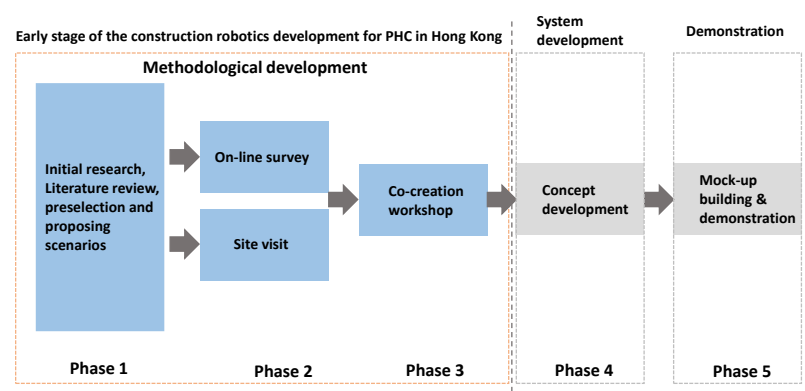

Figure 1. Project phases

The first phase includes initial research, literature review, preselection of the proposed robotics and automation strategies, and proposing use case scenarios. The second phase includes online surveys and site visits. The third phase is co-creation workshops. The fourth phase works on the concept development, detailing and finalisation of the selected system. The fifth phase includes a final demonstration of the system, construction of the demonstration mock-up, validation of the design 
concept, and planning for future work as well as recommendation for future development. This paper will methodically illustrate from phase 1 to phase 3 of the ongoing project and explore how to use applied research strategies in an early stage decision-making procedure when conducting this type of industry-related and technology-focused consultancy project [6]. The paper also presents current research findings and raises questions in regard to how to address the identified challenges with proposed feasible solutions.

\subsection{Background development}

During the 1980's, the Japanese construction sector put huge investments into $R \& D$ for developing construction robots and automated construction sites. At the time, a shortage of skilled labour, as a result of ageing society, has been a major concern in the Japanese construction industry [7]. Single-Task Construction Robot (STCR) have been developed to address this issue and to attract young workers to get involved in the industry. In general, STCR is designed to focus on executing one or several specific construction tasks in a dedicated working area. Due to the complexity of the construction project, STCR is very different from the robots in manufacturing in terms of the composition, kinematics, navigation, and function. STCR is normally tailor-made to suite all stakeholders' requirements rather than simply integrated into the construction project.

To be able to successfully adopt STCR, it is crucial to follow the notion of Robot-oriented Design (ROD) [8]. The ROD concept was first conceptualised in 1988 by Thomas Bock and later served as the principle for automated construction and robot-based construction sites around the world. This concept emphasizes the idea that during final on-site construction processes, all design parameters should have been considered at the earlier design and production stages. The building components will be designed to be easily handled by robots during the assembly phase. When developing robotic technology for the construction sector, it is far more diverse and complicated than the operation in manufacturing plants [9].

Nowadays, Hong Kong experiences a similar circumstance such as labour shortage, demographic changes, and the urge of increasing construction efficiency. By implementing robotics and automation technologies might be able to tackle some of the aforementioned issues. However, modern buildings consist of many complex structures, layouts, and subsystems. Also, the construction industry can be influenced by other attributes, for example, economy and policies, so that imposing huge constraints when applying robotic technologies in construction. Hence, in the early development phase, it is vital to be aware of key stakeholder's requirements, understand the existing construction operation, and analytically evaluate the construction process. This method helps the project team to enumerate the current demand, and distinguish the optimum strategy.

In principle, there are several hurdles or levels to achieve construction automation, which includes standardisation, semi-automation, and full automation. Standardisation can be achieved through prefabrication, and the prefabrication rates in Hong Kong is relatively high [10]. Prefabrication was introduced to the PHC projects in the mid-1980s in Hong Kong. Then the Hong Kong Housing Authority (HKHA) has promoted extensively the usage of prefabricated elements and standard reusable formwork in the public sector [11]. The most of the contractors are able to achieve 6-day-perfloor working cycle, thanks to the standardisation in design. Optimistically, due to a high degree of standardisation in the PHC sector, so Hong Kong has the potential and willingness to upgrade to the next level.

During the first phase of the research, the background study was conducted, which includes the typology of the building systems, and the labour market shortage analysis in Hong Kong. CIC has provided exclusive statistical information focused on the public rental housing development contracted by Hip Hing Engineering Co., Ltd at Ex-Kwai Chung Police Married Quarters building. The statistics indicate that the following professions will experience the most skilled worker shortage from 2017 to 2025 , including carpenter for wooden formwork and joiner, plasterer, terrazzo and granolithic worker, interior/exterior finishing, stonemason, refrigeration, ventilation mechanic for assembly, inspection, and maintenance tasks. The background study provides an essential understanding of the current Hong Kong PHC sector as a whole, evaluates the weaknesses and strength, prioritises research objectives, and formulates feasible strategies.

An introduction booklet is produced during the first phase of research, and it was distributed among the selected stakeholders. The booklet serves as an eye opener for the construction industry due to the unfamiliarity of robotic technologies. It also assists the stakeholders in understanding the project objectives, and to demonstrate potential application which can be applied in the Hong Kong PHC sector. Based on the findings from the background studies and internal discussions between TUM, CIC and key stakeholders, there were 22 robotic and automation systems were proposed.

The 22 selected systems were also systematically distributed into three use case scenarios [12]. The scenarios were contemplated based on the evolution of degree of automation, and their ability to be integrated into industry during the course of the proposed development roadmap. The first scenario aims to demonstrate the potential of single task construction 
robots (STCR) to assist profession-specific, physically demanding and repetitive tasks on-site. Under this scenario, there are limited alterations which the existing building has to adopt. There is modest impact on the conventional construction industry and the structural performance of the building. It also serves as the backbone for the future development. The second scenario integrates automatic and semiautomatic construction systems. In this scenario, some of the proposed solutions may require alteration of the existing building design. For instance, a higher degree of prefabrication rate is recommended. The building method may need to adopt the use of robotics and automation. The third scenario illustrates the potential of applying fully automated construction system in Hong Kong. In this scenario, the proposed solution can be applied only if the building is designed in consideration of ROD. This scenario describes the ultimate goal that can be achieved when applying feasible automation and robotics technologies in the construction industry in Hong Kong. The scenarios also functioned as project use cases that allow the stakeholder analysis to be conducted [13].

A value matrix is dedicated to the proposed systems under each scenario to classify the functional, and nonfunctional requirements. For example, in this case, the functional requirements specify the technical specification of the system, the compatibility, the productivity, and the Technology Readiness Level (TRL). The non-functional requirements express the nonmeasurable function or quality of the system, the governmental policies and regulations, the legal matter, feasibility, and sustainability. The value matrix of the proposed 22 systems was distributed out to the selected stakeholders and scored with a value that measures those requirements fulfilling the stakeholders expectations. It also provides the background information for the online survey in the later stage of the project.

\subsection{Online survey}

In the first phase of this consultancy study, TUM has identified a series of automation and robotics technologies which has been proposed to PHC. In order to examine the feasibility of these automation and robotics technologies, as well as their potentials to improve productivity, safety, and quality of the industry, an online survey (powered by Google Forms) is conducted, and its methodology and results are described as follows.

\subsubsection{The survey methodology}

The aforementioned 22 robotic systems in three scenarios are listed in the questionnaire and these systems' technical details are described in the questionnaire. They include: T1 reinforcing bar fabrication positioning; T2 automatic climbing formwork; T3 concrete distribution; T4 concrete levelling and finishing; T5 logistics supply; T6 hoist and positioning; T7 installation and material handling; T8 façade cleaning and exterior finishing; T9 interior painting; T10 interior wall plastering; T11 automated bricklaying; T12 automated interior tiling; T13 robotic marking; T14 exoskeleton; T15 mobile onsite factory; T16 vertical delivery system; T17 building components positioning and handling; T18 façade element installation; T19 prefabrication in HVAC system; T20 sky factory; T21 ground on-site factory; and T22 integrated on-site assembling system.

The survey follows a two-round selection method (adapted from Nanyam, et al., 2015, see Figure 2) [14]. The first round is to examine these proposed systems' feasibility for the PHC in Hong Kong (the primary attribute). Once accepted, all attributes (e.g., feasibility, improvement of productivity, safety, and quality) of these systems are further evaluated. Each question is based on the Likert Scale [15]. In addition, survey participants can leave comments to each technology.

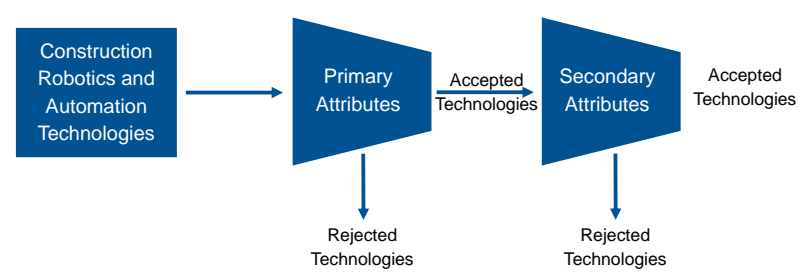

Figure 2. Survey selection method

Equation followed for calculating the TPS of the attributes of each technology:

$$
\mathrm{TPS}=\sum_{i=1}^{5} P i \times W i
$$

- $\quad$ TPS $=$ Technology Preference Score

- $\quad \mathrm{P}=$ Percentage of Preference

- $\mathrm{W}=$ Weighted Value (strongly agree $=100$; agree $=75 ;$ neutral $=50 ;$ disagree $=25 ;$ strongly disagree $=0$ )

- $\quad \mathrm{i}=$ Likert Scale

\subsubsection{The survey results}

The online survey was sent out to more than 200 professionals/stakeholders from Hong Kong construction industry, and 36 effective survey responses have been received. Professionals are from various backgrounds: $36 \%$ of the participants are contractors, $28 \%$ are consultants, $14 \%$ are clients, $14 \%$ are policymakers, 5\% are academics, and $3 \%$ are NGO members. $82.4 \%$ participants have more than 10 years of experience in the construction industry.

After calculating the survey data according to the aforementioned method, the survey results are listed as below. Technologies with a score above 70 are strongly/highly recommended; between 50 and 70 are 
recommended; below 50 are poorly or not recommended. Logistics supply and ground on-site factory are ruled out in the first-round feasibility examination according to the criteria (their feasibility scores are under 50) (Figure $3 \&$ Figure 4).

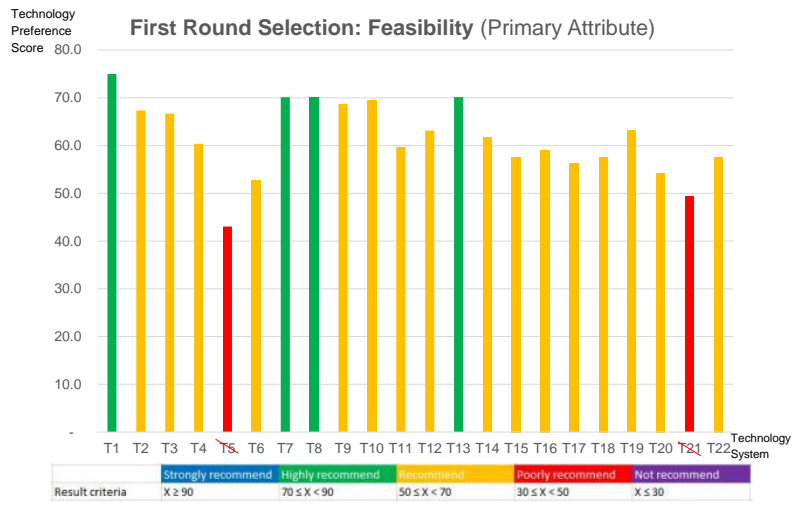

Figure 3. Survey scores of the first round selection

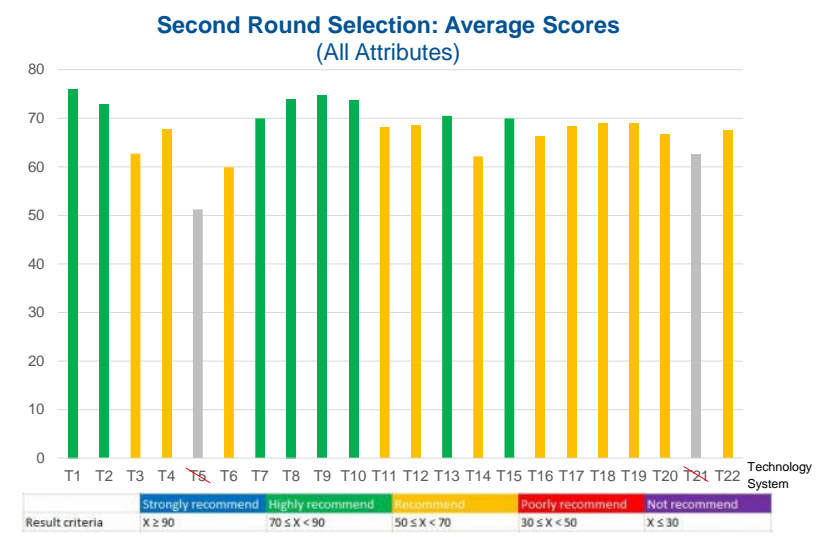

Figure 4. Survey scores of the second round selection

The result of the two-round selection summarised in Table 1 shows that in Hong Kong, the construction robotics and automation technologies are overall approved by the local professionals and stakeholders. The highly recommended technologies are of high priority and thus can be implemented in the near future. The recommended technologies are also demanded, but there is a long way to go before they can be fully implemented. However, due to the actual situation in Hong Kong, some technologies are not practical at the moment, such as T5 logistic supply and T21 ground onsite factory.
Table 1. Final survey results

\begin{tabular}{|l|l|}
\hline & T1 (Reinforcing Bar Fabrication/ Positioning) \\
Highly & T2 (Automatic Climbing Formwork) \\
T7 (Installation and Material Handling) \\
Recommended & T8 (Façade Coating, Painting, Cleaning and Exterior Finishing) \\
Technologies & T9 (Interior Painting Application) \\
& T10 (Interior Plastering Application) \\
& T13 (Robotic Marking) \\
& T15 (Mobile On-site Factory) \\
\hline & T3 (Concrete Distribution) \\
& T4 (Concrete Leveling and Finishing) \\
& T6 (Hoist and Positioning) \\
& T11 (Automated Bricklaying) \\
& T12 (Automated Interior Tiling) \\
Recommended & T14 (Exoskeleton) \\
Technologies & T16 (Vertical Delivery System) \\
& T17 (Floor Slab, Beam, Column Positioning and Handling System) \\
& T18 (Facade Element Installation) \\
& T19 (Prefabrication in HVAC System) \\
& T20 (Sky Factory) \\
T22 (Integrated \& Automated On-site Assembly System)
\end{tabular}

\subsection{Site visit}

Shortly after the online survey, the TUM project team travelled to Hong Kong to conduct a comprehensive onsite case study, which was organised by CIC and Hip Hing Engineering Co., Ltd. The site is located at Ngan Kwong Wan Road in Mui Wo, Hong Kong, and it consists of two residential building blocks (one is 14storey and the other is 16-storey) (Figure 5).
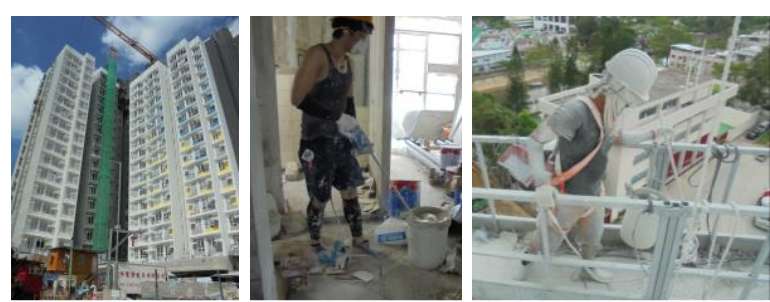

Figure 5. Site visit at Ngan Kwong Wan Road

Both buildings are designed as Home Ownership Scheme project. The main objectives of the on-site study are summarised:

- To understand current workflow, techniques, regulations, and tenders process of the PHC.

- $\quad$ To identify the Key Performance Indicator (KPI) that measures construction success of the project.

- To discuss and exchange ideas with the site manager, skilled labour, and contractors in regards to the implementation of construction robotics in Hong Kong.

- To determine which working process is worth automating.

- To map out feasible concepts and roadmaps for the future development.

The site visit focused on the following key areas:

- Reinforcing bar fabrication/ positioning

- Self-climbing formwork or conventional formwork 
erection process

- On-site logistics and material handling strategies

- Shear wall component hoist, positioning, and installation process

- Prefabricated bathroom component hoist, positioning, and installation process

- Interior finishing process

- Façade coating, sealing, painting, cleaning, and inspection.

Since the case study building was close to the completion stage, limited site activities could be observed. The construction diary and imagery collected throughout the construction process became a valuable resource to analyse the intended key areas. Detailed interviews were conducted with the site manager, engineers, and skilled labour. Interview questions and answers were documented in the site visit report. Potential areas that can be optimised by implementing construction robotics and automation were identified, which include reinforcing bar fabrication, positioning, formwork erection, prefabricated wall assembly, drywall assembly, façade painting, and interior finishing. One interesting finding is that before the site visits the project team considered on-site logistics and material handling as an integral part of the whole construction process, which has huge potential to be automated. However, during the site visit, the project team realised that the construction site is orderly organised yet extremely congested due to the limited on-site space. Therefore, it is challenging to implement robotic delivery systems, such as automated guided vehicle, allocated docking station, and dedicated loading bays on-site. The project manager also mentioned that it is crucial to test and refine the proposed robotic application in a pilot project, in which the biggest challenge is to introduce construction robots into an on-going project without causing any delays.

\subsection{Co-creation workshop}

After the online survey and on-site visit, a number of workshops were organised. These series of workshops were a key milestone of the consultancy study. The workshops aimed to seek practical input from industry experts to 1) evaluate the technical feasibility of adopting construction robotics/automation technologies in actual construction sites, and 2) map out pragmatic action plans for the Hong Kong building industry. Consequently, two Technical (T) Sessions and two Policy (P) Sessions were organised. The workshop participants comprised of a broad range of stakeholders including governmental representatives, developers, contractors, consultants, and industry experts. In total, more than 40 participants joined the two-day workshops. The outputs from the workshops were summarised and presented to the CIC
Committee on Productivity. The data were used to form a roadmap on adopting advanced construction technologies in Hong Kong.

The main objectives of the $\mathrm{T}$ session were to identify the specific tasks and constraints within the on-site PHC that have the potential and are necessary to be upgraded by construction robotics and automation, then to determine the key organisational, technical, functional requirements when implementing construction robotics and automation in the selected on-site tasks. The priority tasks identified from the $\mathrm{T}$ sessions include façade/exterior work, interior plastering/painting, automatic formwork, hoist/positioning system, and welding. Detailed sequences of the sub-tasks were identified based on the existing operation of the tasks. For example, the sub-tasks of façade/exterior work include the installation of gondolas, cleaning and preparing the external wall, skim coating, exterior painting, installing the exterior piping, inspecting façade paint quality, and dismantling of the gondolas. Understanding the detailed work sequence will help the project team to identify the general requirements for the specific tasks, which are:

- $\quad$ The proposed system needs to be flexible and easy to install in the confined space on-site.

- The proposed system needs to be compact, lightweight, and easy to manoeuvre.

- $\quad$ The proposed system needs to be easy to adapt to the different designs of the building.

- $\quad$ The proposed system should avoid using temporary fixtures that will increase installation time.

- $\quad$ The proposed system should consider human-robot interaction. The robotic system hardly completely replaces on-site labour but can work together with labour to enhance overall productivity.

Based on the outcomes from the $\mathrm{T}$ session, the $\mathrm{P}$ session aimed to formulate strategies and action plans on how to implement appropriate technologies for the selected on-site tasks, in which socio-technical issues, work organisation, safety concerns, financial implications, skills requirements, and regulation-related topics were discussed. In conjunction with the potential concerns and opportunities during the implementation of the proposed systems were examined. Subsequently, guidance and potential approaches were forthrightly discussed in terms of how to address economic, managerial, social and political issues when introducing automation and robotics to PHC sector. As a result, industry policies encouraging the adoption of automation and robotics are necessary, which means the government and CIC should consider creating incentive programs for the contractors to adopt robotics and automation in their projects. It is crucial to establish a construction robots supply infrastructure including manufacturers, distributors, training facilities, and maintenance services. 
Moreover, the degree of complexity and automation of the robotic system has to be considered during the early design phase. In addition, feasible business models have to be developed based on the scopes of the key stakeholders.

At the end of the co-creation workshops, a number of key performance indicators were identified, which include safety, labour shortage, improve quality, adoptable, compact and flexible design, acceptance, and improve productivity. A key performance study of the selected system was conducted by TUM project team with a spider chart (Figure 6). The spider chart is used as a metrics to demonstrate a dynamic trend of the influential key performance, and each one is rated by lower to higher variables. For example, in this case, 5 point indicates a better performance score than 4 point. There were 5 finalists chosen for the evaluation, which include façade work and exterior work system, interior painting, plastering system, hoist and positioning system, automatic formwork, and automated welding system.

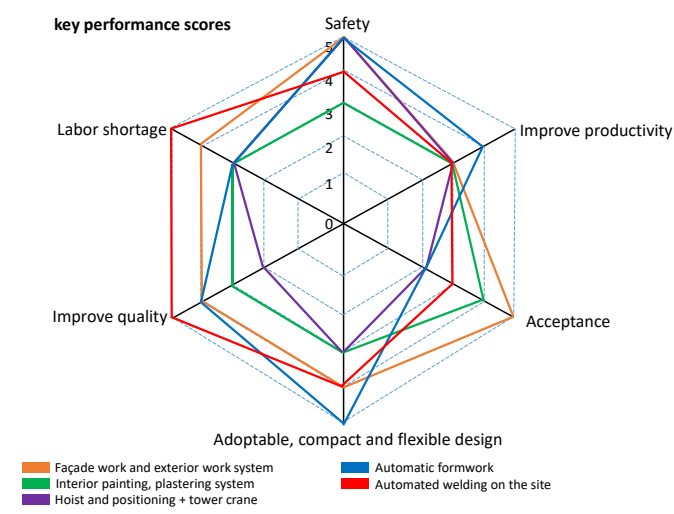

Figure 6. Key performance scores spider chart

The detailed description of the key performance indicators are as follows:

- Safety has been identified as one of the most important criteria for façade and exterior work system, automatic formwork and hoist system, positioning, and tower crane operation.

- The adaptable, compact and flexible design has been identified as the second most dominant measure. It is also pointed out by the participants during the workshops that the proposed system has to be adaptable to the changes in the on-site environment, building layouts, and design features.

- The proposed system needs to address the increasing trend of labour shortage and to improve the finishing quality as well as productivity.

- In general, the acceptance scores indicate that the construction industry is open to the implementation of automation and robotics.

- To convince the stakeholders to adopt automation and robotics on-site, the project team has to carry out a compelling pilot project with attractive incentives with the help of the government.

After discussion with the stakeholders, the project team decided to conduct the next phase of research based on the façade and exterior work system, because 1) it addresses the identified challenges, 2) it achieved balanced key performance scores based on the spider chat, 3 ) it can be constructed as a scale model in an early development stage with given budget, and 4) it can be implemented in a real construction site with minimum disturbance, hence suitable for future pilot project.

\section{Results}

During the project, the initial research identified the main requirements of the stakeholders, as well as the proposed strategies and scenarios for implementing construction robotics and automation in Hong Kong. The initial research forms the academic foundation for later phases. The online survey determined the potential systems that can be developed. However, the result is less conclusive, due to stakeholders' experiences and expertise. Nevertheless, the result has paved the way for the on-site visit. The on-site visit validated the requirements of the frontline workers. The feedback from the on-site visit was consecutive, pertinent and knowledgeable. Thus, the accumulated information helped the project team to build up a convincing argument, and draft research evidence and directions during the co-creation workshop sessions, which systematically formulated technical and practical strategies for further developing the project.

As a result, the façade and exterior finishing robot were chosen to be developed as a stimulator to the PHC industry. The proposed system will be a revelation that demonstrates how to adopt robotics and automation in the conventional construction process. In general, the robot will be highly modularised, which can form various configurations based on the design of the target building. Three application modes were proposed based on a ring concept (Figure 7).

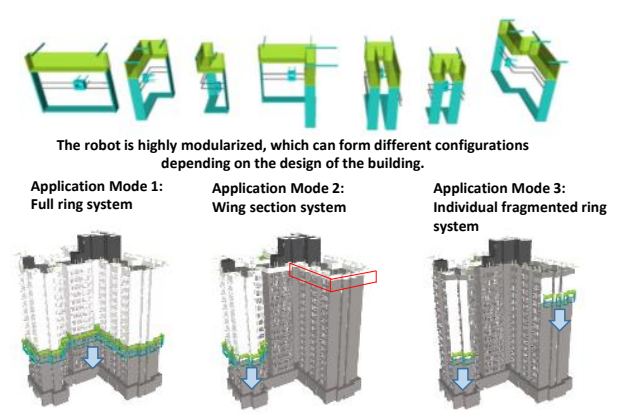

Figure 7. Proposed concept 
The first mode is the full ring mode in which the system can be operated as a whole/partial ring up and down along the building surface according to the project schedule. The second one is the wing section mode in which the system can be operated to cover one wing of the building and then be reassembled to the other wings according to the scheduled work plan. The third one is the individual fragmented ring mode in which the system is only designed to paint a specific surface type. For example, the system only paints flat surfaces without any window openings, indentations or protrusions. Currently, the project team is working on the detailed design of the systems where the degree of automation, kinematics, and end-effectors will be finalised. However, due to intellectual property protection issues, the detailed design cannot be revealed at the moment.

\section{Conclusion}

The consultation project offered an opportunity to perform the systematic study in regard to how to implement robotics and automation technologies in PHC sector from the ground up. Through the initial research, online survey, site visits, and co-creation workshops, the project team have successfully identified the industry demands, stakeholder requirements, yet, narrowed down the research scope and now focuses on the system development as well as real-world implementation. The research findings indicate that the PHC sector in Hong Kong has the potential and willingness to implement construction robotics and automation technology. However, there are also challenges imposed by the existing industry. Many issues and questions cannot be verified at this moment in time, such as the construction industry's reluctance to change, limited understanding of automation and robotics, and lack of robotic infrastructures. How to generate more research incentives, make changes in the government policies, and initiate appropriate business models also need to be taken into consideration. The next phase of the project will be focused on detailing system design, constructing scaled functional mock-up, and disseminating the mock-up to the industry as well as to the public. The research methodology can serve as a guideline when the construction industry executes the similar type of project. In addition, the research will be able to inspire the construction industry to initiate and explore innovative, compatible as well as feasible solutions to the implementation of the robotic application in the future.

\section{Acknowledgements}

The authors would like to sincerely thank the Construction Industry Council Hong Kong (CIC) for initiating and funding this research.

\section{References}

[1] Chiu, R.L., 2007. Planning, land and affordable housing in Hong Kong. Housing Studies, 22(1), pp.63-81.

[2] Liu, A.M.M., 1999. Residential satisfaction in housing estates: a Hong Kong perspective.

[3] Cheng, I., Yeung, C.K.Y., Fung, C.K.Y. and Lai, W.K.W., 2011. Affordable social housing: Modular flat design for mass customization in public rental housing in Hong Kong. In Proceedings of SB11 Helsinki World Sustainable Building Conference. Helsinki, Finland.

[4] Census and Statistics Department, 2016. Hong Kong Annual Digest of Statistics.

[5] Hasegawa, Y., 2006. Construction Automation and Robotics in the 21st century. In International Symposium on Automation and Robotics in Construction (ISARC) (pp. 565-568).

[6] Kothari, C.R., 2004. Research methodology: Methods and techniques. New Age International

[7] Kangari, R. and Miyatake, Y., 1997. Developing and managing innovative construction technologies in Japan. Journal of Construction Engineering and Management, 123(1), pp.72-78.

[8] Bock, T., 2007. Construction robotics. Autonomous Robots, 22(3), pp.201-209.

[9] Bock, T. and Linner, T., 2015. Robot-oriented Design. Cambridge University Press.

[10] Jaillon, L. and Poon, C.S., 2009. The evolution of prefabricated residential building systems in Hong Kong: A review of the public and the private sector. Automation in Construction, 18(3), pp.239-248.

[11] Chiang, Y.H., Chan, E.H.W. and Lok, L.K.L., 2006. Prefabrication and barriers to entry-a case study of public housing and institutional buildings in Hong Kong. Habitat International, 30(3), pp.482-499.

[12] Forsberg, K.M. and H Cotterman, H., 2000. Visualizing project management: a model for business and technical success (No. E14 123). John Wiley and Sons.

[13] Robertson, S. and Robertson, J., 2012. Mastering the requirements process: Getting requirements right. Addison-Wesley.

[14] Nanyam, V. N., Basu, R., Sawhney, A., \& Prasad, J. (2015). Selection Framework for Evaluating Housing Technologies. Procedia Engineering, 123, 333-341.

[15] Likert, R. (1932). A technique for the measurement of attitudes. Archives of Psychology, 22 140, 55. 